\title{
Educación para todos y cualquiera
}

\author{
Education for everyone and anyone
}

\author{
Educação para todos
}

Angélica María García Castillo*

Universidad Distrital Francisco José de Caldas

\begin{abstract}
Citar este artículo así:
García, A. M. (2018). Educación para todos y cualquiera. Revista Enfoques, 3(1), 174-198. http://dx.doi.org/
\end{abstract}

Derechos de autor: Licencia Creative Commons AtribuciónNoComercial-SinDerivadas 4.0 internacional y 2.5 Colombia (CC BYNC-ND 2.5 (O)

Recibido: diciembre 25 de 2017

Revisado: agosto 30 de 2018 Aceptado: septiembre 16 de 2018

* Angélica García, estudiante del Doctorado Interinstitucional en Educación, correo electrónico: angelicagarcia.ps@gmail.com

e 174 
Resumen | El presente documento es una revisión teórica sobre la educación y cómo se han manejado las diferencias de tipo físico, cognoscitivo o cultural, en la población estudiantil. Dichas diferencias, comprendidas como algo inherente a la especie humana y que no pueden ser concebidas como algo no deseable, tienen una presencia inequívoca en el escenario educativo. Se inicia por una revisión del manejo de las diferencias en la educación, desde la Grecia antigua, pasando por diferentes épocas, hasta llegar a la actualidad. Se indaga sobre las pedagogías de las diferencias como una posibilidad del encuentro entre maestros y estudiantes; y como una experiencia educativa innovadora que hace posible la generación de espacios para escucharse a sí mismo, escuchar al Otro y escucharse en interacción, es decir, introducirse en una ética de la mirada. Se establece que la educación inclusiva es un proceso inacabado, con importantes avances que se nutren de experiencias cotidianas, dentro de una red donde también participan autores ajenos al aula convencional. Se debe reconocer y respetar la alteridad de cada sujeto dentro de su realidad y sin visiones distorsionadas.

Palabras Clave | pedagogías de las diferencias, diferencia, otro, ética de la mirada

Abstract | This document is a theoretical review about education and how differences in the student population have been handled, whether physical, cognitive or cultural. These differences, understood as something inherent to the human species, and that cannot be conceived as something undesirable, have an unequivocal presence in the educational scene. It begins with a review on the management of differences in education from ancient Greece, going through different periods until today. The pedagogies of differences are explored as a possibility of the encounter between teachers and students; and as an innovative and enabling educational experience of the generation of spaces to listen to oneself, listen to the other and listen to each other in interaction, that is, to introduce oneself to an ethic of the gaze. It is established that inclusive education is an unfinished process with important advances, which are nourished by daily experiences, within a network where authors from outside the conventional classroom also participate. The otherness of each subject must be recognized and respected within their reality without distorted visions.

Keywords | pedagogies of the difference, difference, other, ethics of the gaze

Resumo | Este documento é uma revisão teórica sobre a educação e como as diferenças na população estudantil foram tratadas, sejam elas físicas, cognitivas ou culturais. Essas diferenças, entendidas como algo inerente à 
espécie humana, e que não podem ser concebidas como algo indesejável, têm uma presença inequívoca no cenário educacional. Começa com uma revisão sobre a gestão das diferenças na educação da Grécia antiga, passando por diferentes períodos até hoje. As pedagogias das diferenças são exploradas como possibilidade do encontro entre professores e alunos; e como uma experiência educacional inovadora e capacitadora da geração de espaços para ouvir a si mesmo, escutar o outro e ouvir um ao outro em interação, ou seja, apresentar-se a uma ética do olhar. Estabelece-se que a educação inclusiva é um processo inacabado com avanços importantes, que são nutridos pelas experiências cotidianas, dentro de uma rede onde também participam autores de fora da sala de aula convencional. A alteridade de cada sujeito deve ser reconhecida e respeitada dentro de sua realidade sem visões distorcidas.

Palavras-chave | pedagogias das diferenças, diferenças, outras, éticas do olhar

\section{Introducción}

El escenario educativo es donde, sin duda, convergen las diferencias inherentes a los seres humanos, por su característica fundacional de apertura a los estudiantes y su carácter formador de sujetos. Sin embargo, al mismo tiempo, se evidencia una fractura entre la escuela y las diferencias; una distancia que a la luz de la educación inclusiva es necesario disminuir, estrechando el espacio entre maestros y estudiantes para darle lugar a un "estar juntos" y escucharse mutuamente. Al parecer, desde el inicio de los tiempos la diferencia se ha comprendido desde una percepción negativa y ha sido objeto de lucha por parte de ciertos grupos sociales, que buscan revindicar las diferencias como lo cotidiano y real, y definir la normalización como un artificio que predomina.

Es relevante revisar las concepciones que se han generado a lo largo del tiempo y encontrar los discursos actuales que apuestan por el respeto, el reconocimiento de todos y cada uno, y la valoración del encuentro entre unos y otros.

\section{Contexto de la educación, el maestro y el estudiante: desde la edad antigua hasta la actualidad}

El concepto de educación aparece desde la Grecia antigua, con un objetivo específico: transmitir oralmente las costumbres y las reglas de una comunidad para formar un tipo de hombre ideal, coherente y determinado. Por ende, la educación fue dirigida a una clase específica: la nobleza. El hombre noble era digno de educación, pues tenía un ideal de virtud

巨॥ 176 
(areté) para el cual debía ser formado. La educación griega fue influenciada por este ideal de areté y, más adelante, se complementó con la noción de nobleza del espíritu (honor), sobrepasando la acepción guerrera y centrando toda su atención en el "yo", en la "apropiación de la belleza" (amor propio). Estos son los primeros vestigios de la aparición del concepto de "personalidad". La educación entra en juego como la acción de formar la personalidad a través del consejo y la dirección espiritual, para lograr la "formación consciente de los jóvenes, de acuerdo con los imperativos de las costumbres cortesanas" (Jaeger, 1957, p. 43), es decir, de acuerdo con un modelo y tipo fijo de ser humano. Entonces, emergió la figura del "mentor", fundada en un objetivo pedagógico, y centrada en el ejemplo. Así, sólo algunos tendrían derecho a llevar este título (Jaeger, 1957; Zingano, 2004).

Sócrates, Platón y Aristóteles se referían a la razón o al intelecto como lo divino de los hombres. Solo las creencias eran relevantes para tomar decisiones, por tanto, sólo quien tenía las creencias verdaderas podía actuar bien. El mentor o maestro era ese mentor selecto. Luego, sobrevendría el dilema de quién sería digno de enseñar la virtud moral. Una búsqueda utópica que Aristóteles logra solucionar haciendo alusión no solo a lo intelectual sino también al uso práctico, que corresponde a "aprehender lo que se debe hacer en una circunstancia" determinada. El mentor o maestro sería, pues, el encargado de la "corrección moral", entendida como el resultado de la formación intelectual (Zingano, 2004, p.70) y el manejo emocional, necesarios para comprender las circunstancias. A través de esta proposición, Aristóteles anunció que el maestro no tenía una posición privilegiada, y también necesitaba una educación emocional. Desde sus inicios, la educación no ha sido para todos; solo para algunos privilegiados (maestros y aprendices), quedando por fuera la mayoría. El ideal del ser no solo se veía reflejado en la educación, sino también a nivel cultural, mediante prácticas de abandono, eliminación o búsqueda de cura de todos aquellos que presentaban signos evidentes de debilidad, enfermedad o malformaciones ${ }^{13}$ (Alegre de la Rosa, 2000).

Contrariamente al concepto griego de la educación como privilegio, bajo el Imperio Romano, la educación fue tarea adjudicada a los esclavos griegos, quienes debían impartirla, y

\footnotetext{
${ }^{13}$ En la actualidad, las creencias sobre los débiles y las prácticas de eliminación de la época antigua se recogen bajo el modelo conceptual de la discapacidad, basado en la prescindencia, en concordancia con una mirada en la que la persona con discapacidad no merecería vivir (Palacios, 2008).
} 
quienes más adelante fueron libertos y enseñaron en escuelas, ya no en casas de familia. Fue así como la escuela se institucionalizó. La educación empezó a verse intervenida por el Estado, pues era este quien asignaba los espacios y los salarios a los maestros. La percepción de la labor del maestro era ambigua, pues oscilaba entre ser una labor indigna o decorosa. Con la llegada del cristianismo, la educación fue sacudida por un cambio radical: los maestros eran quienes conocían la Biblia. Este cambio dio la bienvenida a la educación medieval (Alighiero, 2006; Salas, 2012).

En la Edad Media, aparecen las clases sociales, encabezadas por los reyes y la Iglesia, seguidos de los señores feudales y sus siervos. La Iglesia monopolizaría la educación, fundamentándola en la fe y la lectura de la Biblia y los evangelios. Por lo tanto, la lectura se convirtió en una habilidad totalmente necesaria, en un mundo analfabeta, por lo cual solo los clérigos tenían acceso a la educación. El analfabetismo llevó a la Iglesia a la evangelización, enseñando la fe cristiana a todos los hombres y mujeres, diferenciados según su edad y su clase.

Desde la perspectiva cristiana, en contraste con la tradición greco-romana, la eliminación o abandono de aquellos seres "anormales" era castigada y prohibida, pues se basaban en la piedad como virtud cristiana y el respeto por la vida. Sin embargo, esto no significó que fueran acogidos bajo la doctrina educativa. La misma Iglesia se encargó de asociar las anomalías con contenidos demoniacos y sobrenaturales, de manera que aparecieron los primeros asilos para estas personas, que fueron señaladas como un reflejo de la desobediencia a los principios morales, o de posesiones demoniacas sujetas a exorcismo ${ }^{14}$ (Alegre de la Rosa, 2000; Salas, 2012).

Hacia el final de la Edad Media, todos los maestros eran clérigos, podían ser maestros libres, pero debían tener una licencia para enseñar. Sin embargo, no eran pagos, solo recibían lo que los estudiantes, voluntariamente, les entregaban. Más adelante, aparece la clase burguesa, clase comerciante que emerge gracias al intercambio con Oriente. Lo cual implicó la generación de nuevas riquezas y la decisión de implementar una educación alejada de la

\footnotetext{
${ }^{14}$ Esta mirada de la discapacidad también estaba basada en un modelo de prescindencia, pero con una influencia marcadamente religiosa (Mareño, 2012).
}

\section{$\boldsymbol{\epsilon} \mid 178$}


Iglesia. Nacieron las universidades en donde se instruía a los jóvenes en disciplinas complejas y se ingresaba por méritos académicos. Así, inició el Renacimiento con el movimiento humanista que recobró la atención en el hombre como centro del pensamiento, y da apertura a la Edad Moderna y al desarrollo de la ciencia (Salas, 2012).

En ese entonces, la educación presentó un cambio radical, al convertirse en un "bien comercial", de manera que si se requería un buen maestro era necesario pagarle. Por esta misma razón, la educación empezó a tener fines específicos (especializarse) según las necesidades de esta clase social. Simultáneamente, surgió el protestantismo en la Península escandinava y países como Alemania, Holanda, Inglaterra, entre otros, como respuesta crítica a la Iglesia y sus sacerdotes. El resultado fue la Reforma, un movimiento religioso que promulgaba el libre pensamiento de los seres humanos frente a la Biblia y la invitación a su libre interpretación. Esta idea principal promovió la educación para todos e invitó a los intelectuales a empezar a pensar en las formas de generar aprendizaje de manera idónea, esto es, de acuerdo con sus habilidades. Aparecen, entonces, pensadores como Comenio (1592-1670), quien revolucionó la pedagogía y la didáctica ${ }^{15}$; John Locke (1632-1704) con su propuesta de formación de ciudadanos, o Rousseau (1712-1778) con su propuesta antropológica de la pedagogía, centrada en las habilidades de los estudiantes (Salas, 2012).

Es en la transición de la Edad Media a la Edad Moderna cuando se empieza a reflexionar sobre la educación de las personas con deficiencias y anomalías. Intelectuales como Pedro Ponce de León (1509-1584) y Juan Pablo Bonet (1579-1633) desarrollaron en España experiencias educativas con niños sordos, que sistematizaron y escribieron. Más adelante, Charle Michel de L’Epée (1712-1789) creó la primera escuela para sordos, que luego se convertiría en el Instituto Nacional de Sordos de Francia; en 1784, Valentín Haüy (1745-1822) crea en París la primera escuela para niños ciegos. En el siglo XIX, la obligatoriedad de la enseñanza trajo consigo la educación para personas con carencias físicas, psíquicas o sociales. Esto dio apertura a todo un campo de estudio que se ha desarrollado hasta la actualidad y, así mismo, cambió el sentido de la educación, pues esta empezó a basarse en una pedagogía que acercaba al maestro y el

\footnotetext{
15 "La didáctica nace en el siglo XVII y forma parte de un proyecto social de educación general para todos. Así, la didáctica constituye un elemento básico en la utopía que la modernidad asigna a la escuela" (Díaz Barriga, 1998, citado en Bolívar, 2008, p.44).
} 
estudiante, en donde el primero inculcara el amor por el saber, por encima de los contenidos en sí mismos (Sánchez, 1994; Alegre de la Rosa, 2000, y Salas, 2012).

La Revolución Industrial y la Revolución Francesa marcarían el paso a la Edad Contemporánea, que inició a finales del siglo XVIII y, según los historiadores, se mantiene hasta el siglo XXI. La Revolución Industrial tuvo impactos de toda índole, y la educación no sería la excepción. La creciente necesidad del proletariado (antes artesanado), de mejorar sus conocimientos para mejorar su desempeño en las fábricas, obligó a disminuir la restricción de acceso a la educación, que hasta entonces regía para las clases populares. Así también, se promovió la pedagogía como la ciencia encargada de buscar la innovación en las metodologías y didácticas para enseñar a grupos numerosos, incluyendo a los niños. Esto se hizo bajo los preceptos básicos de Rousseau y redundó en: la organización de contenidos temáticos coherentes con las necesidades sociales de ese entonces; la reglamentación de la educación para mediados del siglo XIX, y el ingreso de grupos marginales a la educación (Sánchez, 1994; Salas, 2012).

A mediados de 1800, en diferentes países de Europa, se crearon asociaciones destinadas a la institucionalización y atención de "niños deficientes" y, con ellas, nació el interés por la enseñanza especial, con carácter curativo y rehabilitador. Cabe resaltar que, a pesar de que nació el interés por las personas con "deficiencias", no todas eran tratadas de la misma manera, pues la historia evidencia que los primeros estudios se adelantaron, especialmente, con personas con discapacidad sensorial, mientras que las personas con alguna discapacidad intelectual o mental ${ }^{16}$ eran recluidas en instituciones y percibidas por la sociedad como personas enfermas y necesitadas de la caridad (Cabrera, 2012; Salas, 2012; Sánchez, 1994).

En 1850, aparece la Pennsylvania Training School, escuela creada por Séguin y dedicada al tratamiento de la deficiencia mental. Hacia 1900 aparecen las primeras "Escuelas de Educación Especial" para la población con "retardo mental" ${ }^{17}$ y, simultáneamente, aparece el

\footnotetext{
${ }^{16}$ Discapacidad intelectual y mental son conceptos actuales, pues en la época se empleaban términos como "idiotas", "imbéciles" o "débiles mentales". Además, catalogaban dentro del mismo concepto a las personas con características de los dos tipos de discapacidad.
}

${ }^{17}$ La primera clasificación que se hace sobre la deficiencia mental, conocida también como retraso mental (RM), fue realizada • 
profesor de educación especial. Lo que significó la división de los maestros según la población que instruirían. En 1905, Binet desarrolló una forma de medida de la inteligencia que dio inicio al concepto de "edad mental" y "coeficiente intelectual". Las investigaciones de Binet estaban orientadas a demostrar que la educación podía mejorar las capacidades de las personas con bajo coeficiente intelectual, a través de la educación especial. De manera paralela, salían a la luz los escritos de Darwin (El origen de las especies, 1859) y los descubrimientos genéticos de Mendel (1865), que generaron un movimiento eugenésico en el imaginario social que tendría impacto de larga trayectoria, en especial respecto de las personas con discapacidad. En este momento de la historia existían dos corrientes contrapuestas: por un lado, la corriente médica asistencial y, por el otro, la corriente pedagógica curativa ${ }^{18}$ (Alegre de la Rosa, 2000; Cabrera, 2012; Katz, Rangel y Lazcano, 2010).

El siglo XX se caracterizó por las guerras entre países y potencias mundiales. La educación de la época propendía por un ideal basado en la Escuela Nueva y la Pedagogía Activa. Sin embargo, la distancia con las verdaderas prácticas era abismal, pues estas se caracterizaban por la rigidez, la memorización, la disciplina, etc. Aparecieron autores como Dewey y Russell, que se dedicaron a estudiar la educación y realizaron valiosos aportes vigentes hasta la actualidad. En este siglo se inició una estrecha relación entre la Pedagogía y la Psicología, dando nacimiento a diversas escuelas y corrientes pedagógicas ${ }^{19}$, y animando estudios novedosos como los de Piaget, quien hizo importantes aportes a la Pedagogía, desde su Psicología del Desarrollo, (Salas, 2012).

Estas corrientes educativas y pedagógicas fueron pensadas para las personas que no presentaban "anomalías". Pero, de manera paralela, se tendría que pensar en aquellas que sí las presentaban, ya que cada vez eran más las personas con deficiencias, causadas por las

por el psicopedagogo belga Ovide Decroly, quien a su vez elaboró métodos de enseñanza de la lectoescritura y fundó el Instituto Laico de Enseñanza Especial (Sánchez, 1994). Este término nace en el marco de un modelo rehabilitador de la discapacidad, con bases biológicas, que centra la "anomalía" en la persona, pero que, a su vez, considera que pueden ser rehabiltadas o normalizadas (Palacios, 2008 y Mareño, 2012).

${ }^{18}$ Dos corrientes basadas en un modelo rehabilitador de la discapacidad.

${ }^{19}$ Asociacionismo, introspeccionismo, intencionalismo, funcionalismo, conductismo, gestalsismo, operacionalismo, cogniscionismo, estructuralismo, entre otras. 
guerras. La discapacidad empezó a ser asociada con la insuficiencia que debía ser erradicada (especialmente la discapacidad física y sensorial), pero también con la obligación de la sociedad de compensar a estas personas con pensiones de invalidez y programas de rehabilitación. Las personas con discapacidad intelectual no corrieron con la misma suerte, ya que fueron víctimas de atroces experimentos en los campos de concentración y/o llevadas a la guerra. Los que no murieron, una vez salieron de los campos o de los ejércitos, volvieron al encierro en instituciones. Pero también cabe rescatar que en 1923, en España, fueron reconocidas las Necesidades Educativas Especiales (NEE) de los niños con discapacidad (Cabrera, 2012; Palacios, 2008).

En aras de completar lo incompleto o de normalizar lo anormal, la educación aparece como herramienta para la rehabilitación de las personas con discapacidad y fue el Estado el encargado de esta población. Si bien, inicialmente, la educación para la rehabilitación se consideró un beneficio para las personas con algún tipo de discapacidad causada por la guerra, no tardó en ampliarse dicho beneficio para cualquier persona con discapacidad, independientemente del origen de su deficiencia. Se puede ver que, a pesar del cambio en la percepción de las personas con discapacidad, se transitó de un modelo de prescindencia, que las veía como el reflejo del pecado o de expresión divina, a un modelo rehabilitador que los veía como anormales (enfermos), suceptibles de normalizar (curar), con limitaciones derivadas de la deficiencia (Foucault, 1992; Moreno, 2011; Palacios, 2008).

La década de los años 60 fue un hito en la historia de la educación. Aparecen los movimientos estudiantiles en varios países, exigiendo la trasformación de la vida escolar, su democratización, y la igualdad en la relación maestro-estudiante. Así, también aparecen las reivindicaciones sociales de grupos hasta entonces marginados, como grupos étnicos y de mujeres. Se dice que en esta época se retomaron los preceptos del siglo XVIII de Comenio y Rousseau, para llevarlos a la práctica. También cambió el modo de ser del conocimiento y, por lo tanto, la educación no podía seguir siendo la misma. Ya no era solo el Estado el garante de la educación; ya no era el único que la agenciaba. En el escenario social resplandecían modalidades educativas no formales, con gran acogida social. Lo que significó un gran reto para le educación formal, pues debía reconocer los diversos lenguajes y subjetividades que empezaban a emerger, ya que, finalmente, todos convergían en la escuela (Álvarez, 2012; Salas, 2012). 
Fue un gran momento para el desarrollo de la educación como campo de investigación y ciencia, con la conformación de sociedades científicas y la producción escrita en revistas especializadas. El estudio de la educación dejó de ser aislado y empezó a ser un fen,atz, Rangel \& Lazcano, 2010, civestigci a favor de los ciudadanos en esta situcias. mucho metnias y de mujeresogniscionismo, esómeno social, que lo impulsó desde diferentes disciplinas. Aunque se intensificaron los estudios sobre educación, también nació la división entre pedagogía y educación. La primera se centró en el docente, el estudiante y la escuela (enseñanza); la segunda, abarcó aspectos mucho más amplios que producían conocimiento (investigación) para que los maestros lo reprodujeran. En medio de este auge, la educación especial también tuvo grandes desarrollos, en especial por el interés en los métodos, técnicas y programas que facilitarían la incorporación de las personas con discapacidad en la escuela. ${ }^{20} \mathrm{~A}$ esto se le sumó el interés de los gobernantes por proclamar leyes a favor de los ciudadanos con esta condición y crear programas de investigación sobre el tema, en las universidades (Álvarez, 2012; Cabrera, 2012; Katz, Rangel y Lazcano, 2010; Viñao, 2002).

A comienzos de los años ochenta, se presentaron cambios importantes en la educación para personas con discapacidad, con la denominada "Era de la integración escolar" y la aparición de leyes sobre la escolarización conjunta y la atención integral, basadas en el precepto de normalización, bajo el cual se evaluaba el rol social de las personas con discapacidad y su capacidad de adquirir habilidades para desenvolverse en sociedad, en comparación con las personas sin discapacidad. Era su pasaporte para ser incluidos, sin dejar de lado que la "anormalidad" seguía siendo percibida negativamente; por eso debía ser normalizada. En los años noventa, se empieza a hablar, incipientemente, de la "Educación inclusiva". En la Declaración Universal de los Derechos Humanos (1948), ya se hacía alusión a la necesidad de garantizar la enseñanza no segregadora, pero es durante la conferencia de 1990 de la UNESCO (Tailandia), cuando se hace pública la idea de inclusión y se promueve la máxima de la educación para todos. En 1994, la Conferencia de Salamanca extendería a nivel internacional la idea de educación inclusiva como principio y política educativa (Cabrera, 2012; Moriña, 2004; Palacios, 2008; UNESCO, 1994).

\footnotetext{
${ }^{20}$ Se debe anotar que estas innovaciones pedagógicas no implicaban una verdadera inclusión de esta población en la escuela, pues se las educaba separadamente en aulas especiales o exclusivas.
} 
En el mundo de finales del siglo XX, el surgimiento de la educación inclusiva se da en paralelo con un cambio en la concepción de la discapacidad. Desde un modelo social, ${ }^{21}$ se revisan las intervenciones orientadas a esta población y se concluye que ya no deben estar dirigidas al individuo, sino a la sociedad, con el fin de lograr igualdad de oportunidades y acceso, para evitar situaciones de discapacidad relacionadas con las barreras sociales. En el ámbito de la educación, se empezó a pensar en una educación adaptada a las necesidades de todos, pues todos los seres humanos son diferentes. A su vez, este cambio impacta directamente la denominada educación especial, que hasta ese entonces era impartida por docentes específicos. Es decir, la responsabilidad de la formación de personas con discapacidad se traslada a cualquier persona, a todo aquel que se denomine docente. $Y$ se entiende que es necesario individualizar la enseñanza de acuerdo con ritmos de aprendizaje particulares (Palacios, 2008).

La educación inclusiva trae consigo el término diferencia como un concepto amplio que no recae sobre unos "diferentes", sino sobre las diferentes necesidades de aprendizaje de los individuos. Esta concepción convoca un cambio inminente en la ética de la escuela, que empieza a valorar la diferencia. También coincide con el concepto diversidad ${ }^{22}$ como "posibilidad de cada uno de los sujetos de reconocerse en su yo individual y siendo reconocido por el yo colectivo, mcomo opuestos complementarios. tros/otrostos de reconocerse en su yo individual y sienso reconocido por el yo colectivo, mgativoás allá de los estándares universalmente aceptados" (Miguez, 2009, p. 50). Lastimosamente, estos objetivos loables -de inclusión en general y educación inclusiva- se han interpretado de muchas maneras. Se han asimilado la diferencia ${ }^{23}$ y la diversidad a la deficiencia, conllevando prejuicios negativos y manteniendo la dualidad nosotros/otros (otredad, alteridad), como opuestos no complementarios. Interpretación

\footnotetext{
${ }^{21}$ El modelo social tiene dos presupuestos: el primero reza que las causas de la discapacidad son preponderantemente sociales; el segundo, que las personas con discapacidad pueden aportar a la sociedad, en relación directa a los grados de inclusión y aceptación de la diferencia (Palacios, 2008).
}

${ }_{22}$ Diversidad, como concepto de la Antropología por excelencia, corresponde a una categoría descriptiva de las razas, las culturas y los pueblos humanos (Skliar, 2012).

${ }^{23}$ Diferente como categoría resultante de la teoría evolucionista que considera que los organismos mejor adaptados para sobrevivir se diferencian de aquellos que no lo están (Skliar, 2012).

\section{$\boldsymbol{\epsilon} \mid 184$}


que perjudica a la población con discapacidad. Estas concepciones sociales, basadas en la desigualdad y con el lastre moderno de la normalización, motivaron la creación de un movimiento actual que, basado en el modelo social, busca la reivindicación de los derechos de las personas con discapacidad ${ }^{24}$ y su reconocimiento como ciudadanos: con derecho a tener derechos (Miguez, 2009; Palacios, 2008; Skliar, 2002).

En la actualidad, en el campo educativo prevalecen discusiones interesantes con respecto a los conceptos de inclusión, diversidad y diferencia, que buscan aproximarse a prácticas y comprensiones de la diferencia en términos tan amplios que acojan a todos los seres humanos y, a la vez, lo suficientemente específicos que atiendan las necesidades particulares de cada persona. Simultáneamente, persisten las discusiones y prácticas basadas en la prescindencia (con fachadas políticamente correctas) y la rehabilitación. Lo que significa que coexisten diferentes formas de comprender al "otro" y de buscar un lugar en el que quepan "todos". La escuela, siendo un producto de la modernidad, se ha tornado en el centro de atención y de acogida de esta simultaneidad de discusiones que, por supuesto, también involucran al maestro y al estudiante, su configuración y su relaciatoradiversidad , su configuracidiante, su configurachora la llamada a acoger estas discusiones a normalizaci colectivo, mgativoón.

\section{La educación para todos y cualquiera, el rol del maestro y la configuración del estudiante}

Los primeros vestigios de la educación para personas con discapacidad aparecen en la historia hacia el siglo XVI, con las experiencias que Pedro Ponce de León y Juan Pablo Bonet construyeron con personas sordas. Es hasta el periodo de 1800-1900, con las experiencias de Itard y la llegada de la era de las instituciones, que aparece la educación especial como disciplina especializada dentro del campo de la educación. Así mismo, se origina la figura del pedagogo especial y nace el concepto de Necesidades Educativas Especiales (NEE), basado en el modelo rehabilitador de la época. Hacia 1960, la educación ya era un derecho de las personas con discapacidad, pero fue utilizada como un mecanismo para rehabilitar sus

\footnotetext{
${ }^{24}$ La Convención sobre los Derechos de las Personas con Discapacidad es un ejemplo de esta lucha, a la cual se han adherido y ratificado, a la fecha, 173 países. Es un instrumento internacional de protección de los Derechos Humanos y la Dignidad de las Personas con Discapacidad, que incluso está por encima de las facultades de la Constitución Pol. la redefiniciódadidas, 1994; cultades de la Constitucia la actualidad dicaci modernidad de la normalizaci colectivo, mgativoítica de cada país (ONU, 2006).
} 
capacidades. Adicionalmente, estas personas eran educadas separadamente de las personas sin discapacidad (Cabrera, 2012; Katz, Rangel y Lazcano, 2010).

Es en la década de los años 80, cuando se presenta la era de la integración escolar, el momento en el que personas con y sin discapacidad compartían una escuela por primera vez. Dicho compartir ofrecía diferentes opciones: inclusión en aula especial a tiempo parcial, inclusión en aula especial a tiempo completo, inclusión en clases ordinarias, maestro de apoyo, y apoyo de equipos psicopedagógicos, entre otras (Cabrera, 2012).

En 1994, la Declaración de Salamanca (UNESCO) insta a los Estados miembros a volcar todos los esfuerzos para instaurar una educación para todos, con especial énfasis en los niños y niñas con $\mathrm{NEE}^{25}$, y entrega un marco de acción a las escuelas con directrices sobre los cambios estructurales necesarios para lograr este tipo de educación, incluyendo la invitación a desarrollar el modelo de Rehabilitación Basada en la Comunidad (modelo RBC) ${ }^{26}$ y la confirmación de que todos los maestros debían ser formados para atender a esta población, no solo los Educadores Especiales. El objetivo era que todos los niños tuvieran educación de calidad y la sociedad cambiara las actitudes de discriminación.

La integración escolar fue duramente criticada en varios aspectos: por el hecho de haberse basado solo en los derechos de las personas con discapacidad y NEE, pues dejaba de lado otros grupos minoritarios; por el pobre impacto que generó en la necesaria reestructuración escolar; por suponer la conveniencia de adicionar a estas personas a la escuela, generando una doble estructura para atender a la población con NEE; por la falta de formación de los maestros para atender la población con discapacidad y NEE, y por la poca flexibilidad curricular (Parrilla, 1999a).

Con el tránsito hacia el modelo social de comprensión de la discapacidad, la Educación Especial ha entrado en discusiones sobre su pertinencia y, así mismo, sobre la disciplina que

\footnotetext{
${ }^{25}$ En el contexto de la Declaración de Salamanca, el término necesidades educativas especiales se refiere a "todos los niños y jóvenes cuyas necesidades se derivan de su capacidad o sus dificultades de aprendizaje" (UNESCO, 1994, p. 6).

${ }^{26}$ La rehabilitación basada en la comunidad es un "método específico de desarrollo comunitario que tiende a rehabilitar, ofrecer igualdad de oportunidades y facilitar la integración social de las personas con discapacidad" (UNESCO, 1994, p. 18).
}

\section{$\boldsymbol{\epsilon} \mid 186$}


la acoge como marco contextual. En la actualidad, reposa en la Didáctica ${ }^{27}$ como ciencia de la educación, desde donde se comprende a la Educación Especial como una lente peculiar para estudiar los conceptos de enseñanza, aprendizaje, instrucción, formación, métodos, materias, profesor, alumno, y sus relaciones con respecto a la educación de personas con discapacidad (Parrilla, 1997). Necesariamente, el Educador Especial cambia su rol, tornándose en un apoyo fundamental para el maestro, dentro de un proceso de inclusión educativa ${ }^{28}$.

En el año 2000, aparece el Index for Inclusion (Booth \& Ainscow, 2000) como documento maestro y manual internacional que propende por el desarrollo del aprendizaje y la participación en las escuelas. Este documento, que fue promovido por la UNESCO, marca un hito en la historia de la educación, pues hace referencia a las escuelas inclusivas, trascendiendo la integración escolar y llevándola a otro nivel. Su objetivo inicial es la autoevaluación de las escuelas y la implementación de la metodología de investigación-acción en el trabajo escolar. También, elimina el concepto de NEE e incluye los términos barreras de aprendizaje y participación, lo cual involucra a todos los estudiantes, no solo a las personas con discapacidad. La inclusi"desarrollo de la inclusión y d)mo a ser educado junto a sus iguales y d) la necesidad de que la sociedad asegure eñ desarrollo ón educativa se enmarca en la educación inclusiva, un concepto amplio que comprende que "las barreras, al igual que los recursos para reducirlas, se pueden encontrar en todos los elementos y estructuras del sistema: escuela, comunidad, políticas" (Booth \& Ainscow, 2000, p. 9). En la inclusión, se espera que la diferencia sea valorada positivamente.

Hay cuatro ideas principales en el modelo de la educación inclusiva: "la inclusión como un derecho; como vía para garantizar la equidad en la educación; como derecho de cualquier persona a ser educado junto a sus iguales, y la necesidad de que la sociedad asegure el desarrollo de la inclusión" (Moriña, 2004, p. 19). Como se puede observar, la educación inclusiva es un tema que no solo concierne a la escuela, pues es una cuestión social muy

\footnotetext{
${ }^{27}$ Didáctica como espacio conceptual y operativo, como campo de conocimientos, de investigaciones, de propuestas teóricas y prácticas que se centran, sobre todo, en los procesos de enseñanza y de aprendizaje (Parrilla, 1997). Actualmente, esta ubicación de la Educación Especial en la Didáctica se encuentra en debate.

${ }^{28}$ Es el caso de Canadá, en donde el Educador Especial se denomina "profesor de método y recursos" y desempeña un papel de asesoramiento a los maestros, basado en su saber y experiencia, para lograr la inclusión educativa en las escuelas de los Distritos (Porter, 2007).
} 
acorde con el modelo social del que se ha venido hablando. Esta propuesta también es bastante cuestionada actualmente, en especial porque en varias ocasiones se entiende como sinónimo de la integración, y porque en las prácticas educativas no se evidencian cambios sustanciales con respecto al modelo anterior, a sus experiencias de discriminación y de exclusión. Esta tensión ha hecho que autores como Skliar (2000; 2002; 2012), Larrosa (2014) , Castiblanco (2014), Contreras (2014), y Duschatzky y Skliar (2001), entre otros, estudien la educación inclusiva y sus posibilidades actuales, desde la perspectiva de la educación para todos y cualquiera, en donde la escuela tiene un rol de gran importancia en todos sus niveles estructurales. Dentro de dichos niveles están el rol del maestro y sus prácticas, el rol del estudiante, y la relación entre ellos dos como actores que hacen parte de una sociedad, sin dejar de lado que cada uno tiene un conocimiento local y situado (Geertz, 1994). Además, estos estudios se sustentan en la propia voz de los grupos marginados, que expresan la gravedad y la urgencia de eliminar las barreras sociales (Barton, 2009).

La propuesta de la educación inclusiva está atravesada por una concepción del ser humano como sujeto de derechos, en donde cada persona es un fin en sí misma y su dignidad está arraigada en esa esencia, y no necesariamente se evalúa por su aporte a la sociedad. El principal valor por el que se aboga es el de igualdad, encarnado en la igualdad de oportunidades y en la defensa de la dignidad. Nussbaum, filósofa que ha trabajado desde la perspectiva de los derechos, propone el Enfoque de las Capacidades como base para lograr el respeto por la dignidad humana, pues las capacidades son atribuibles a todas y cada una de las personas. La autora enlista diez capacidades humanas básicas: "vida, salud física, integridad física, sentidosimaginación-pensamiento, emociones, razón práctica, afiliación, relación con otras especies, juego, control sobre el propio entorno" (Nussbaum, 2007, p. 88 y 89), y considera que la educación debe ser el medio que promueva un enfoque basado en el reconocimiento de las capacidades humanas de todos (Moreno, 2011; Palacios, 2008).

De acuerdo con Echeita y Duck (2008), "hacer efectivo el derecho a la educación exige garantizar que todos los niños, niñas y jóvenes tengan, en primer lugar, acceso a la educación, pero no a cualquier educación sino a una de calidad con igualdad de oportunidades" (p. 1). Las prácticas orientadas hacia este objetivo tendrían un gran impacto social, en la medida que se mitigarían las posibilidades de discriminación y de exclusión. El paso a la inclusión educativa requiere cambios de diferentes tipos, a saber: liderazgo para la implementación del 
programa inclusivo en la escuela, nuevo rol del educador especial, y apoyos para los maestros para desarrollar clases inclusivas (Porter, 1997). Este cambio también implica un cambio en la mirada hacia una mirada holística que no se centre en la deficiencia o en el diagnóstico, sino en los procesos y en el desarrollo de cada persona, en escuchar su voz, basándose en una actitud totalmente positiva por parte de las personas de la comunidad educativa, de manera que estén dispuestas a hacer de la inclusión una realidad posible.

Diferentes autores coinciden en que la educación inclusiva es una meta aun inalcanzada, que a veces puede tornarse utópica. Sin embargo, hay experiencias educativas que han logrado este objetivo y hay autores que hacen una apuesta por la inclusión, sin desconocer que la gran pregunta está orientada no al qué sino al cómo; que hay que tratar de dilucidar la discusión sobre la diferencia, la alteridad y la diversidad, etc., de manera que no se traduzcan como meros eufemismos del término discapacidad. Asimilar los conceptos de diferencia y diversidad, desde la perspectiva de la discapacidad o las NEE, es una tendencia especialmente presente en la escuela, donde suele vaciarse sobre las prácticas cotidianas un contenido particularmente negativo, que arrastra el lastre de su propia historia y no es el más idóneo ni adecuado. La tradición epistémica colonialista facilita la producción y reproducción de conceptos marginalizantes y de relaciones de poder, como son las expresiones: "los diferentes", "los diversos", los "otros", que avalan a "unos" para hablar de "otros", para definirlos, categorizarlos y caracterizarlos de acuerdo con modelos conceptuales y términos que aparecen como social y científicamente aceptados (Villa y Villa, 2012) .

Cabe advertir que la diferencia toma una fuerza impertinente cuando se absorbe en el diferente, cuando deja de pertenecer a la especie y se traslada a lo individual, con una carga negativa casi imposible de desprender. Desde esta perspectiva se produce una dualidad entre el estudiante educable y el que no lo es, y la especialización del maestro para cada uno de los grupos. En esta concepción de diferencia se acentúan argumentos para que unos, denominados nosotros, hablen sobre los denominados "otros"; un "otro" configurado como fuente de aquello que no se cree ser o no se quiere ser y que, por supuesto, no hace parte de un "nosotros". Bajo esta misma perspectiva de la diferencia, aparece malinterpretado el concepto de diversidad, en donde "Ios otros son los diversos", trasladando el concepto a todos los "excluidos". 
¿Quiénes son esos "otros"; quién los designa y asigna a esa categoría de alteridad? El Otro no es diferente sino distinto, con una historia, una cultura, una exterioridad; no ha sido respetado, no se le ha dejado ser Otro, se lo ha incorporado a lo que le es extraño, se lo ha alienado (Dussel, 1996). Cada uno debería tener su propia voz. No se trata de reconocer la voz de los otros, pues con escucharla sería suficiente, respetando su esencia humana, el derecho a existir de todos y cada uno. Y, como refiere Dussel (1996), respetarlo; el "respeto es silencio, pero no silencio del que nada tiene que decir, sino del que todo tiene que escuchar porque nada sabe del Otro como Otro" (p. 78). La corriente epistémica poscolonial invita a descentralizar los modelos conceptuales tradicionales, que se han retomado para hablar de "los otros", y así configurar categorías conceptuales más cercanas a lo esencialmente humano y al reconocimiento inicial de las igualdades y las diferencias de cada persona. Lévinas (1993) considera que al Otro se lo reconoce como semejante y al mismo tiempo como exterior; es la relación con un misterio, con algo que no es el yo mismo, que es diferente en razón a su alteridad. Skliar (2000) refiere que la diferencia debería ser comprendida como algo inherente a la especie humana; que no puede ser concebida como algo "no deseable" o que "tarde o temprano volverá a la normalidad" (pp. 7-8). Se trata simplemente de reconocerla, pues está ahí, en cada sujeto, en uno mismo.

Por su parte, el concepto diversidad busca revindicar aquellos grupos históricamente denominados "marginales" y aboga por procesos de inclusión (social, educativa, laboral, etc.). Este concepto nace al interior de la Antropología como categoría descriptiva de las razas, las culturas y los pueblos humanos, e ingresa al campo educativo a la par con el concepto de inclusión, en aras de romper con las imágenes homogéneas que se tenían de los escolares. La diversidad está vinculada al concepto de totalidad heterogénea, entendida como el resultado de las relaciones entre las personas de un grupo. Este concepto invita a un cambio en la forma de pensar, hacer y actuar frente a la realidad inminente de la diferencia. Se puede afirmar que es un concepto, a su vez social y educativo, que plantea que todas las personas son distintas, con diferencias personales, sociales y culturales, debido a las cuales no deben ser excluidas, pues, desde esta perspectiva, precisamente esas diferencias son valoradas positivamente. En el ámbito educativo, la valoración positiva de la diferencia conlleva una cultura de la diversidad que apunta directamente a los principios de la educación inclusiva y la inclusión educativa (Parrilla, 1999b; Leiva, 2012; Skliar, 2012). 
La actualidad de la escuela inclusiva está llena de retos, de cambios necesarios a nivel organizacional, y de procesos. Estos cambios no son el inicio, al contrario, deben ser el resultado del impacto ocasionado por el principio rector de la inclusión: el cambio en la mirada. Situarse en el discurso pedagógico de la diversidad y la diferencia no se puede reducir a buscar las técnicas y estrategias para enseñar en el aula, pues remite a un ejercicio profundo de reflexividad individual por parte de todos los actores de la comunidad educativa (administrativos, familias, docentes, estudiantes). Un ejercicio que debe transformar sus prácticas, barreras y percepciones, pues el papel personal juega un rol de gran importancia en la inclusión; debe desembocar en un diálogo permanente, desde una actitud de apertura y acogida mutua. Generalmente, la mirada es educada para ver el mundo desde posiciones modernistas que indican lo que debe ser mirado y lo que se debe invisibilizar. Es decir, la mirada no es solo un acto biológico, sino también cultural, y tiene prácticas asociadas a todo nivel. La reflexión, la vuelta sobre la propia mirada, es necesaria para pensar en una educación inclusiva como nuevo espacio de encuentro educativo, con nuevas prácticas, contemplado como un acontecimiento en donde todos y cualquiera se encuentran para ser y estar, experimentar y disfrutar juntos (Castiblanco, 2014a; Leiva, 2012).

El diálogo depende siempre de otro -mínimo deben participar dos sujetos-, es temporal y creativo, es impredecible, es un suceso, un encuentro en el que se está inmerso y exige capacidad para escucharse entre interlocutores y sumergirse en una conversación que de verdad sea una conversión donde se susciten cambios, se genere un lenguaje común, un lugar común que facilite la comprensión. El diálogo está atravesado por una ética discursiva que está abierta a la participación y simetría de los interlocutores. Desde esta ética se reconoce a cada ser humano como dotado de competencia comunicativa, siendo esta competencia un punto clave para el reconocimiento de los derechos de cada persona. Se trata de una posición ética, de un sujeto que mira a otro sujeto, de un sujeto maestro que mira a un sujeto estudiante y viceversa; una mirada atenta a la singularidad, sensible: se trata de una pedagogía de las diferencias (Castiblanco, 2014a; Esquirol, 2005).

La educación debe ser un acto de implicación con el Otro y con uno mismo, que trascienda la retórica, para generar prácticas, al interior de la escuela, que reconozcan la singularidad, que no obliguen a ninguno a ser lo que no es, que acompañen al estudiante en sus trayectorias, en el desarrollo de una vida digna, y que se basen en una educación de la 
mirada, orientada a estar prestos a la novedad que deviene de la historia personal, los deseos, las dificultades, etc. En el marco de la educación inclusiva y desde la inminencia de la mirada reflexiva personal, el maestro representa los principios de la pedagogía de las diferencias que incluye el desarrollo de la dignidad, la percepción de lo singular, la actitud abierta a escuchar, la proximidad y la comprensión de las diferencias como un cúmulo de posibilidades para educar a cualquiera y a cada uno (Contreras, 2014; Skliar, 2012). En términos de Wittgenstein (citado por Veiga Neto, 2009) "si pensar y decir están en el plano de las prácticas, en el contexto de la vida misma, es posible, entonces, pensar otros pensamientos, decir otros decires" (p. 128), es posible cambiar la ética de la mirada.

\section{La ética de la mirada en la educación para todos y cualquiera}

Lévinas define la ética como una óptica que deriva de una significación de la diferencia; que estructura originariamente lo humano y la humanidad, e incluye el cuestionamiento del "Mismo" por la presencia del "Otro". Se trata de ser consciente y sobrepasar la lógica del "Otro domesticado - Otro del Otro", que es concebido como otro yo, o que se trata de atraer hacia sí mismo para unificar la diferencia y dominarlo. Se trata de sobrepasar la lógica del Otro como el extranjero, el huérfano, el despojado, que está ubicado no en la otra orilla, sino en otro nivel (menor-mayor). El Otro es aquello que yo no soy: es la relación con un misterio, con lo infinito, con la incertidumbre, con su alteridad como esencia expresada en su rostro, en un encuentro cara a cara, que debería resultar en una respuesta de acogida y hospitalidad, de responsabilidad para con el Otro como proximidad ética, despojada de la soberbia y el egoísmo del Yo (Lévinas, 1993; 2002; 2006).

Derrida (2000) define la hospitalidad como un principio de todas las culturas, como una ética que acoge sin reservas, sin condiciones, que se basa en una ley única de la diferencia y la similitud, y que, por ende, es una relación de tensión, lejos de ser fácil y serena, pues presupone dejar de mirar como lo hacemos, dejar de "traducir" las diferencias, usurpando la voz de los demás (Bhabha, citado en Duschatzky y Skliar, 2001). El encuentro con el Otro es experiencia facilitadora del conocimiento de ese Otro; experiencia que busca eliminar sentimientos de miedo u odio a lo desconocido, o de encasillamiento por características específicas que interrumpen la continuidad de las personas y las hace desempeñar papeles que no les corresponden. Es un encuentro basado en una ética de la alteridad, entendida como 
la posibilidad de que las diferencias de aquellos marcados como Otros puedan ser encontradas éticamente, con apertura en la mirada promotora de nuevas relaciones intersubjetivas (Lévinas, 2006; Soler, 2017). Esta es la mirada que se necesita en la educación inclusiva: pensar y vivir la escuela de una manera diferente, expresada en comprensiones genuinas de cada estudiante como parte del sistema educativo, no solo adherido al sistema estándar que excluye a algunos. Una educación que no se base en el déficit, sino en las necesidades de todos y cada uno, en cuanto a ritmos de aprendizaje y diferencias particulares.

La crítica y la reflexividad del discurso, así como de las prácticas pedagógicas establecidas, deben ser elementos cotidianos de aquella escuela que promueve una educación inclusiva, buscando desmanchar la mirada, apartarse de las miradas controladoras, para lograr nuevas formas de relación entre unos y otros, y dejar de preguntarse por la forma de incluir a los Otros. En el caso de los maestros, quizás se trate sobre todo de pensar en cómo enseñar desde perspectivas innovadoras, más allá de juzgar el cómo o el qué aprende el Otro; quizás no se trate de recibir más capacitaciones sobre cómo enseñar a los diferentes, sino de involucrarse, responsabilizarse e implicarse en la relación con cada estudiante, tener la disponibilidad para escucharlo y comprender su esencia, inherentemente diferente. Y así, permitirse una transformación y reencausar la experiencia en la escuela desde una necesaria nueva ética y desde unas pedagogías de las diferencias (Zardel, 2010). Estas pedagogías nuevas, singulares, innovadoras, solo pueden ser resultado de las experiencias y de la relación con el Otro, desde una actitud abierta y permisiva a la afectación, a dejarse tocar por el Otro; abierta al cambio que redunde de eso que, en términos de Dussel (1996), "es una conciencia ética, es la capacidad que se tiene de escuchar la voz del Otro, de conmoverse" (p.16).

La escuela debe ser el espacio para la expresión de la alteridad, de lo distinto que se puede ser, de lo singular, de la mirada de cada uno para construir mundos posibles, inciertos, no solo un mundo basado en la certidumbre, pues la diferencia es cambiante, se moviliza y necesita flexibilidad y cambio en la perspectiva de cada actor involucrado. En la escuela se debe impartir (dar) una educación más cercana, basada en el diálogo como un encuentro en el que, como refiere Esquirol (2005), "cada interlocutor encuentra al Otro y se encuentra a sí mismo en el Otro" (Pág. 75); un encuentro en el que el maestro es consciente de su incompletud y redefine sus certezas. La incompletud y la incertidumbre podrían ser entendidas como un reto motivador para seguir profundizando en el Otro, dejarse sorprender por sus diferencias, 
sumergirse en la experiencia -en eso que me pasa; no en lo que hago-, pues la experiencia no se trata de la acción o de las prácticas, sino de lo que se siente cuando acontece lo inesperado, cuando se permite la sorpresa, por más riesgosa y expositiva que sea.

Las propuestas curriculares, metodológicas, etc. son importantes y existen en el escenario educativo, pero no pueden ser una camisa inamovible; deben configurarse como un andamiaje flexible, abierto a la retroalimentación y la participación de la comunidad educativa, que oriente y facilite la enseñanza y el aprendizaje, y la construcción de las propias trayectorias. Se hace relevante, entonces, la disposición del maestro para sumergirse en las pedagogías de las diferencias, que son una forma de "habitar el oficio" (Larrosa, 2014). Forma de habitar que debe ser cuidada de las inadecuadas formas de mirar (ética de la mirada); que podría ser dada desde una postura investigativa no tradicional, aquella que sospecha y debate lo establecido, que busca al interior y en los momentos de verdad con el Otro; formas de habitar el oficio que son formas de ser y vivir singulares, desprovistas de determinismos, que se toman el tiempo de pensar y repensar sus prácticas, de considerar el qué y el cómo. En definitiva, desde unas pedagogías de la presencia, que son la única manera de lograr esas reflexiones y ser sensitivo para lograr relaciones equitativas con cada estudiante y consigo mismo, pues es, al mismo tiempo, un viaje de autoconocimiento de sus propias posibilidades y límites, para luego intentar desnaturalizar los modos en que nos han enseñado a mirar.

Se trata de trasladar la mirada, acostumbrada a centrarse en "los otros", para reposarla sobre nosotros mismos. Dejar de preocuparse tanto por el aprendizaje "del otro", por las capacitaciones para enseñar a "los otros", por las capacidades "del otro" para lograr un estándar determinado, y, por el contrario, detenerse en la capacidad que tiene su presencia de otorgarnos el tiempo, la pausa para repensarnos, quizás de-construirnos y volvernos a construir como seres humanos. Podría decirse que es una invitación a una reflexión autoética, a partir del espejo, para mirar por las fisuras y ver qué más se logra encontrar sobre las miradas previas; una invitación a renunciar al poder y el estatus social instituido del maestro y, ojalá, descubrir elementos transformadores para miradas futuras no solo hacia el Otro, sino también hacia el espacio educativo, buscando que sea un espacio no convencional, regido por la iniciativa de maestros con pensamientos y sentimiento alternativos sobre la educación, preparados para "acompañar a los estudiantes, como gesto mínimo necesario en la experiencia pedagógica” (Castiblanco, 2014b, p. 12). 


\section{Conclusiones}

La educación inclusiva es el resultado de un largo proceso en la historia de la educación y de profundas reflexiones de movimientos sociales que buscan la reivindicación de derechos y el reconocimiento de los seres humanos en su esencia y existencia. La inclusión es un proceso inacabado en todos sus frentes, con avances, pero con retrocesos y fijaciones en el pasado que se deben remover en aras de proporcionar mejores opciones para todos, especialmente en la educación.

La educación inclusiva, que se enmarca en la comprensión de las diferencias y las similitudes de los estudiantes, no puede simplemente remitirse a lineamientos escritos y estandarizados por expertos en educación, pues es necesario vivir cotidianamente la experiencia inclusiva, para lograr acoger a todos y cada uno. Es imprescindible construir un espacio en el que todos puedan conocerse y generar relaciones que den cabida a los propósitos de la escuela.

El escenario educativo no solo está compuesto por los docentes y los estudiantes, existe toda una red social alrededor de esta relación que debe participar desde una postura ética que resignifique nuestra relación con cualquier otro, que respete y valore las diferencias de cada sujeto. Se trata de una ética de la mirada que debe ser el resultado de un ejercicio de autorreflexión continuo y de la renuncia a poderes preestablecidos; una ética de la mirada que supera el estar preparado o no y se centra en el gesto de acompañar la vida de cada estudiante, $y$, ¿por qué no?, de cada sujeto participante de la comunidad educativa.

La alteridad, su esencia reflejada en cada sujeto, en cada estudiante, no solo debe ser reconocida y valorada, sino también respetada y profundamente comprendida en sus expresiones más genuinas. Expresiones que pueden ser tan armónicas como incómodas, pues no se trata de reducir la alteridad a percepciones idílicas del Otro sino aceptar sus originalidades, en esencia y en existencia.

Hacer referencia a "todos y cualquiera" acoge a cualquier persona, pues no se trata de etiquetar a algunos o de generar eufemismos, sino, por el contrario, de apostarle a que todos se puedan sentir acogidos bajo estos términos, y respetados en sus diferencias y por sus diferencias. Al final, esta propuesta es un reto, pues desmitifica la necesidad de formación 
especializada, para atender poblaciones específicas, y naturaliza la posibilidad de cada persona de adoptar una posición, una actitud ética frente al Otro, cualquier Otro, porque no se trata de los demás, sino de cada uno.

\section{Referencias}

Alegre de la Rosa, O. (2000). Diversidad Humana y Educación. Málaga, España: Ediciones Aljibe.

Alighiero, M. (2006). Historia de la educación. México: Siglo XXI Editores.

Álvarez, A. (16 de octubre de 2012). Módulo: Aproximación al concepto de pedagogía y tendencias pedagógicas. Programa de maestría en desarrollo educativo y social, pp. 1-54.

Barton, L. (mayo-agosto de 2009). Estudios sobre discapacidad y la búsqueda de loa inclusividad. Observaciones. Revista de Educación, 137-152.

Bolívar, A. (2008). Didáctica y currículum: de la modernidad a la postmodernidad. Málaga, España: Aljibe.

Booth, T., \& Ainscow, M. (2000). The index for inclusion: developing learning and participation in schools. London: CSIE.

Cabrera, A. (2012). Paradigmas de la educación especial. México: Red Tercer Milenio.

Castiblanco, I. (2014). Dar la mirada. ¿Es posible una mirada de la ética en fotografía? Diplomado superior en pedagogías de las diferencias. Buenos Aires: Flacso Virtual.

Castiblanco, I. (2014). La experiencia en su laberinto. Una conversación hablada y escrita sobre la experiencia de enseñar arte en Casa de la Cultura de la Calle (CACUCA). Diplomado superior en pedagogías de las diferencias. Buenos Aires: Flacso Virtual.

Contreras, J. (2014). Percibir la singularidad, y también las posibilidades, en las relaciones educativas ¿Una pedagogía de la singularidad? Diploma superior en pedagogías de las diferencias. Buenos Aires: Flacso Virtual.

Derrida, J. (2000). La hospitalidad. Buenos Aires, Argentina: Ediciones La Flor.

Duschatzky, S., y Skliar, C. (2001). Los nombres de los otros. Narrando a los otros en la cultura y la educación. Barcelona, España: Laertes.

Dussel, E. (1996). Filosofía de la liberación. Bogotá, Colombia: Nueva América.

Echeita, G., y Duck, C. (2008). Inclusión educativa. Revista iberoamericana sobre calidad, eficacia y cambio en educación, 6, 1-8.

E $\mid 196$ 
Esquirol, J. (2005). Uno mismo y los otros. De las experiencias existenciales a la interculturalidad. Barcelona, España: Herder.

Foucault, M. (1992). La verdad y las formas jurídicas. España: Gedisa.

Geertz, C. (1994). Conocimiento local. Ensayos sobre la interpretación de las culturas. Barcelona, España: Paidós. Jaeger, W. (1957). Paideia. México: Fondo de Cultura Económica.

Katz, G., Rangel, G., y Lazcano, E. (2010). Discapacidad Intelectual. México: Mc Graw Hill.

Larrosa, J. (2014). Cine y diferencias. Pedro Costa: ¿cómo entrar en el cuarto de Wanda? Diplomado superior en pedagogías de las diferencias. Buenos Aires: Flacso Virtual.

Leiva, J. (2012). Educación intercultural y convivencia. Málaga, España: Aljibe.

Lévinas, E. (1993). El tiempo y el otro. Barcelona, España: Paidós.

Lévinas, E. (2002). Totalidad e infinito (Sexta ed.). Salamanca, España: Sígueme.

Lévinas, E. (2006). Ética como filosofía primera. A parte rei. Revista de filosofía, 43, 1-21.

Mareño, M. (2012). El saber convencional sobre la discapacidad y sus implicaciones en las prácticas. En Almeida, M. y Angelino, M. Debates y perspectivas en torno a la discapacidad en América Latina. Argentina: UNER.

Miguez, M. (2009). Construcción social de la discapacidad. Montevideo, Uruguay: Trilce.

Moreno, M. (2011). Infancia, políticas y discapacidad. Bogotá, Colombia: Universidad Nacional.

Moriña, A. (2004). Teoría y práctica de la educación inclusiva. Málaga, España: Aljibe.

Nussbaum, M. (2007). Las fronteras de la justicia. Consideraciones sobre la exclusión. Barcelona, España: Paidós.

Organización de las Naciones Unidas para la Educación, la Ciencia y la Cultura. (1994). Declaración de Salamanca y marco de acción. Salamanca, España: UNESCO.

Organización de las Naciones Unidas. (2006). Convención sobre los derechos de las personas con discapacidad y protocolo facultativo. Estados Unidos: ONU.

Palacios, A. (2008). El modelo social de la discapacidad: orígenes, caracterización y plasmación en la Convención internacional sobre los Derechos de las Personas con Discapacidad. Madrid, España: CINCA. 
Parrilla, Á. (1999). Más allá del conocimiento intelectual sobre la diversidad. Profesorado, revista de currículum y formación de profesorado, 3, 1-16.

Parrilla, Á. (1997). La construcción de la educación especial desde la didáctica: el perfil de un debate académico. Enseñanza, 15, 231-240.

Parrilla, Á. (1999). Unidad en la diversidad: itinerario formativo para una escuela de todos. Revista interuniversitaria de formación de profesorado, 36, 157-166.

Porter, G. (1997). Critical elements for inclusive schools. En S. J. Pijl, C. Meijer, y S. Hegarty, Inclusive education: a global agenda (pp. 68-81). Londres: Routledge.

Porter, G. (2007). Puesta en práctica de la educación inclusiva., (pp. 1-14). San Sebastián.

Salas, J. (2012). Historia General de la Educación. México: Red tercer Milenio.

Sánchez, E. (1994). Introducción a la educación especial. Madrid, España: Editorial Coplutense.

Skliar, C. (2000). Discursos y prácticas sobre la deficiencia y la normalidad. En P. Gentil, Códigos para la ciudadanía. La formación ética como práctica de la libertad. (pp.1-13). Buenos Aires: Santillana.

Skliar, C. (2002). Alteridades y pedagogías o ... ¿Y si el otro no estuviera ahí? Educación y Sociedad, 79, 85-123.

Skliar, C. (2012). Acerca de la alteridad, la normalidad, la anormalidad, la diferencia, la diversidad, la discapacidad y la pronunciación de lo educativo. En M. Almeida, M. y, M. Angelino, (Eds), Debates y perspectivas en torno a la discapacidad en América Latina (pp. 185-194). Argentina: UNER.

Soler, S. (2017). Mira, un negro. Racismo, identidad, lenguaje y educación. Manuscrito inédito.

Veiga-Neto, A. (2009). Nietzsche y Wittgenstein: herramientas para pensar la diferencia y la pedagogía. Mutatis Mutandis, 2 (1), 122-133.

Villa, W., y Villa, E. (2012). Identidad, de-centralidad y narrativas de acción. Fragmentos de Cultura, 22, $141-152$.

Viñao, A. (2002). La historia de la educación en el siglo XX. Una mirada desde España. Revista Mexicana de Investigación Educativa, 15, 223-256.

Zardel, J. (2010). Diferencias particulares. Pluralidad, subjetividad y alteridad. Diplomado superior en pedagogías de las diferencias. Buenos Aires: Flacso Virtual.

Zingano, M. (2004). Paideia, virtud intelectual y virtud moral en la antigüedad. En C. García (Ed.), Historia de la filosofía antigüa (Vol. 14, pp. 55-75). Madrid, España: Trotta. 